\title{
BMJ Open Children and Teens in Charge of their Health (CATCH): A protocol for a feasibility randomised controlled trial of solution-focused coaching to foster healthy lifestyles in childhood disability
}

Amy C McPherson, ${ }^{\circ 1,2,3}$ Elaine Biddiss, ${ }^{1,4}$ Lorry Chen, ${ }^{5}$ Paige Terrien Church, ${ }^{5,6}$ Janke F de Groot, ${ }^{7,8}$ Sarah Keenan, ${ }^{5}$ Gillian King, ${ }^{1,9}$ Toni Lui, ${ }^{1}$ Desiree B Maltais, ${ }^{10,11}$ Chantal Mérette, ${ }^{12}$ Hélène Moffet, ${ }^{10,11}$ Fiona Moola, ${ }^{1,2,3}$ Heidi Schwellnus ${ }^{5}$

To cite: McPherson AC, Biddiss E, Chen L, et al. Children and Teens in Charge of their Health (CATCH): A protocol for a feasibility randomised controlled trial of solution-focused coaching to foster healthy lifestyles in childhood disability. BMJ Open 2019;9:e025119. doi:10.1136/ bmjopen-2018-025119

- Prepublication history for this paper is available online To view these files, please visit the journal online (http://dx.doi org/10.1136/bmjopen-2018025119).

Received 29 June 2018 Revised 20 November 2018 Accepted 17 January 2019

\section{D) Check for updates}

(C) Author(s) (or their employer(s)) 2019. Re-use permitted under CC BY-NC. No commercial re-use. See rights and permissions. Published by BMJ.

For numbered affiliations see end of article.

\section{Correspondence to} Dr Amy C McPherson; amcpherson@hollandbloorview. ca

\section{ABSTRACT}

Introduction Children with physical disabilities are rarely included in interventions to promote healthy lifestyles, despite being at higher risk for suboptimal dietary and physical activity behaviours. The Children and Teens in Charge of their Health study explores the feasibility and acceptability of conducting a randomised controlled trial (RCT) of a strengths-based, solution-focused coaching intervention for improving and sustaining physical activity and healthy dietary habits in children and young people with physical disabilities.

Methods and analysis Thirty children aged 10-18 years with a diagnosis of spina bifida or cerebral palsy who are able to set healthy lifestyle goals will be recruited from two children's rehabilitation hospitals in Ontario, Canada. Participants will be enrolled in the study for twelve months. All participants will receive standard care and printed information about healthy lifestyles. Of the 30 participants, 15 will be randomised to receive a coaching intervention for the first 6 months. Health indicators and psychosocial outcomes will be assessed by blinded assessors four times: at the start of the trial, immediately postintervention (6 months after randomisation), and at 3 and 6 months postintervention ( 9 and 12 months after randomisation, respectively). Predefined success criteria will be used to assess the feasibility of trial processes such as recruitment, attrition, stratification and intervention fidelity. Acceptability and perceived impact of the intervention will be explored qualitatively.

Ethics and dissemination The study has been approved by Holland Bloorview Kids Rehabilitation Hospital's Research Ethics Board (Ref: 17-752). A knowledge translation planning template will be used to ensure our findings have maximum reach.

Trial registration number NCT03523806.

\section{INTRODUCTION}

\section{Background}

The WHO's Global Strategy on Diet, Physical Activity and Health Promotion highlights that physical activity and dietary habits are central

\section{Strengths and limitations of this study}

This study focuses on the feasibility and acceptability of using solution-focused coaching in paediatric rehabilitation to promote healthy lifestyles in children with spina bifida and cerebral palsy, who are routinely excluded from health promotion research.

The study will identify if a later efficacy trial is warranted and if so, inform the processes, resources, management and methodology of such a study.

- A study strength is the rigorous methodology, including the use of randomisation, blinding and a priori success criteria, combined with in-depth qualitative inquiry.

- Participants will all be recruited from two centres in one part of Canada, which may reduce the generalisability of the findings.

to disease prevention and lifelong health. Canadian children and youth (herein 'children') have increased health risks as their activity levels are drastically lower than recommendations. ${ }^{2}$ The situation is even more critical for children with disabilities, representing $4.2 \%$ of Canadian children and rising. ${ }^{3}$ Due to complex and intersecting factors, children with physical disabilities (CWPD) are typically more sedentary, have lower rates of physical activity and have poorer quality diets than their peers without a disability. ${ }^{4}$ These factors can lead to exacerbated mobility and functional restrictions, osteoporosis, pressure ulcers, anaemia, obesity and reduced overall health and well-being. ${ }^{5}$ This is particularly true for young people with spina bifida (SB) and cerebral palsy (CP), two of the most prevalent non-progressive childhood physical disabilities. ${ }^{6}$ Both populations frequently experience considerable barriers to engaging 


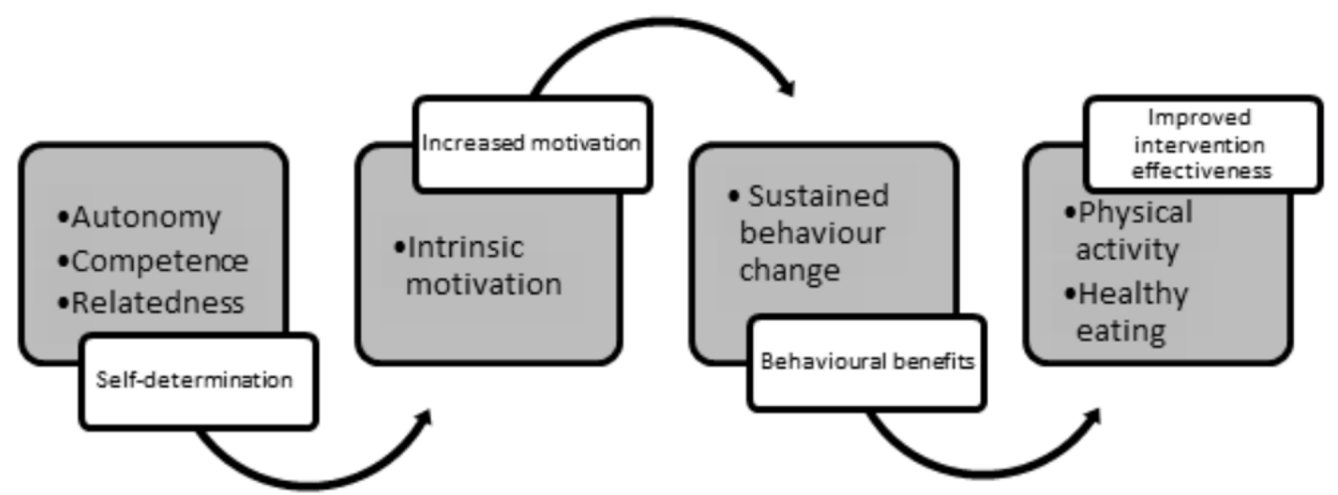

Figure 1 Link between self-determination theory, behavioural change and outcomes underpinning the intervention.

in physical activity and consuming an optimal diet; this threatens their health, independence and quality of life both in childhood and beyond. ${ }^{78}$

Despite the clear importance of healthy lifestyles in CWPD, a comprehensive scoping review ${ }^{9}$ and related literature have shown that: (1) CWPD have far fewer opportunities to engage in health promotion programmes than their peers without disabilities ${ }^{10}$; (2) Although structured exercise/dietary interventions can be efficacious, they are often unsustainable due to the extensive resources required $^{11}$; and (3) CWPD often need support to identify healthy lifestyle activities that are engaging and grounded in their abilities and daily life. ${ }^{12}$

A new intervention paradigm that produces sustainable results without undue burden (on children, families and healthcare services) is therefore urgently required to address the health promotion needs of CWPD. Interventions must empower children and their parents to make lifestyle changes that are personally meaningful in order to promote motivation and encourage sustainable changes. ${ }^{13}$ Interventions must also consider the child's circumstances (individual, environmental, familial) to ensure that healthy behaviours such as physical activity and diet can be integrated into everyday life and thereby have long-lasting impact. ${ }^{14}$ A strengths-based coaching approach may meet all of these requirements.

\section{Solution-focused coaching in paediatrics}

In coaching, clients are guided to identify their own goals, develop strategies to meet them and monitor their performance. ${ }^{15}$ Solution-focused coaching in paediatric rehabilitation (SFC-peds) has been recommended as a coaching model for working with children with disabilities, due to its strong theoretical basis and ability to be customised to children and families' resources, environmental settings, child age, developmental stage and abilities. ${ }^{16}$ SFC-peds combines coaching principles with aspects of brief solution-focused therapy to work in a strengths- based manner with children and families in a rehabilitation context. Using positive reframing and strategic questions, the coach supports clients to identify goals that are personally meaningful to them and develop practical attainment strategies to work towards them. ${ }^{16}$
Using a strengths-based approach such as SFC-peds is a departure from the deficit model usually employed by rehabilitation research (ie, what a child can't do), even though strengths-based approaches been shown to be more efficient and less costly than problem-based approaches. ${ }^{17}$

\section{Theoretical framework}

The primary aim of coaching is to enhance self-determination, that is, the feelings of choice and control over one's life. ${ }^{18}$ Self-determination theory posits that there are three basic psychological needs essential for behaviour change $^{19}$ : (1) Autonomy, the opportunity to make meaningful choices ${ }^{20}$; (2) Competence, also termed 'self-efficacy, ${ }^{16}$ an individual's innate sense of belief in their ability to be successful at a particular activity ${ }^{21}$; and (3) Relatedness, feelings of support and acceptance that provide affirmation. ${ }^{22}$ The resulting intrinsic motivation is a powerful mechanism to foster sustained behaviour change through genuine interest, satisfaction and engagement. ${ }^{19}$ It is operationalised in coaching through the use of strategic questions to help children identify personally meaningful goals and develop practical solutions to move toward a vision of their 'preferred future' (facilitating feelings of autonomy); empowering children to assume ownership over their goals and develop robust self-regulatory behaviours (enhancing competence or self-efficacy); and the use of active listening, empathy and affirmative language (facilitating relatedness). ${ }^{16}$ 23-25 Figure 1 depicts the relationship between self-determination, behaviour change and outcomes, which underpins this study.

\section{Feasibility studies}

Despite being a promising approach, no randomised controlled trials (RCTs) have employed SFC-peds to promote healthy behaviours with CWPD. Prior to running a fully powered efficacy trial, it is essential to obtain evidence of feasibility, especially for complex interventions that have multiple interacting components and/ or target multiple behaviours (such as SFC-peds).${ }^{26}$ Feasibility studies rigorously examine the processes, resources, management and science of the intended efficacy trial. ${ }^{27}$ As one part of assessing feasibility, it is also critical to 
evaluate the acceptability of interventions for the target population, as well as those allocated to the control arm (eg, acceptability of group allocation), and the perceived burden of undertaking assessments. ${ }^{28}$ Feasibility studies help ensure that resources are invested in efficacy trials likely to generate clinically meaningful results ${ }^{26}$ and therefore have maximum impact on healthcare knowledge and outcomes.

Our primary objective is therefore to evaluate the feasibility of conducting an efficacy trial of SFC-peds, part of which includes the acceptability of the intervention to stakeholders. Our secondary objective is to determine the responsiveness of selected outcome measures to a SFC-peds coaching intervention over 12 months.

This protocol adheres to the Standard Protocol Items: Recommendations for Interventional Trials guidelines for reporting of clinical trial protocols (http://www.equatornetwork.org/reporting-guidelines/spirit-2013-statementdefining-standard-protocol-items-for-clinical-trials/) .

\section{METHODS AND ANALYSIS \\ Design}

We will use a feasibility RCT design ${ }^{29}$ with two groups. Both groups will receive the same printed materials on healthy diet/physical activity and continue to receive standard care from their existing clinicians. The participants randomised to the intervention group (SFC-peds) will work with an SFC-peds trained coach for up to eight sessions over 6 months. A 6-month intervention is supported by meta-analyses of health promotion studies for typically developing childre ${ }^{30}$ and adults. ${ }^{31}$ The feasibility of trial processes, management and resources will be assessed quantitatively. The acceptability of the intervention, potential mechanisms of change and barriers to implementation will be explored qualitatively. ${ }^{32}$

\section{Sample and recruitment}

Participants will be aged 10-18 years, diagnosed with SB or CP and live within approximately 2 hours of one of two children's rehabilitation hospitals in Ontario, Canada. These populations were selected due to the prevalence of the diagnoses, ${ }^{6}$ as well as their high levels of sedentary activities and dietary challenges. ${ }^{33} 34$ Full inclusion and exclusion criteria can be found in table 1. Potential participants meeting the age and diagnosis criteria will be identified from medical records/caseloads by clinical staff and receive information about the study. The research coordinator will follow-up with them and screen for the remaining inclusion/exclusion criteria, answer any queries and identify those wishing to participate.

\section{Sample size}

Feasibility studies do not assess intervention efficacy and therefore do not require formal sample size calculations. ${ }^{35}$ The sample size $(\mathrm{n}=30)$ was set as the minimum needed to assess the key feasibility issues, which are to assess recruitment success and show whether testing
Table 1 Study inclusion/exclusion criteria

\begin{tabular}{ll} 
Child inclusion criteria & Child exclusion criteria \\
\hline $\begin{array}{l}\text { Between the age of } 10 \text { and } \\
18 \text { years. }\end{array}$ & $\begin{array}{l}\text { Surgery in past 6months or } \\
\text { next } 12 \text { months impacting } \\
\text { physical activity or dietary } \\
\text { intake. }\end{array}$ \\
$\begin{array}{ll}\text { Diagnosis of spina bifida or } \\
\text { cerebral palsy. }\end{array}$ & $\begin{array}{l}\text { Medical condition severely } \\
\text { restricting diet. }\end{array}$ \\
$\begin{array}{l}\text { Has capability to execute } \\
\text { independent body movement } \\
\text { with or without a device. }\end{array}$ & $\begin{array}{l}\text { Underweight }(<5 \text { th percentile } \\
\text { for age). }\end{array}$
\end{tabular}

Cognitively able and willing to Receiving specialist dietetic set physical activity or dietary services.

goals.

\section{Can communicate in English}

and respond to questions

requiring some reflection/

insight.

Has a home internet

connection.

\begin{tabular}{l}
\hline Parent inclusion criteria \\
\hline Primary caregiver to a study \\
participant. \\
Can communicate in English. \\
\hline
\end{tabular}

procedures, coaching goals and follow-up sessions are consistent across groups, mobility levels and sites. Fiften SFC-peds participants within the intervention group will suffice to show a tendency $(p<0.10)$ of behavioural change assessed by Goal Attainment Scaling (GAS; see list of outcome measures), equal to an effect size of 0.55 with a power of 0.80 . Post hoc estimates of variance will be key, as they will inform the power calculations of a later efficacy trial. ${ }^{35}$ This sample size is also considered adequate for the proposed qualitative work. ${ }^{36}$

\section{Randomisation}

Once participants have provided written informed consent to the research coordinator, they will complete all baseline measures followed by randomisation into one of the two groups. Randomisation occurs after baseline testing to inform stratification, which will be by age (10-13 years vs $14-18$ years); sex as assigned at birth (male vs female); and ambulatory/mobility level (ambulation without limitations [Gross Motor Function Classification System (GMFCS) level 1] vs limited/no ambulation: GMFCS levels II, III, IV). The PLAN procedure of SAS/STAT software will assign group allocation, which will then be implemented by the research coordinator. Randomisation block size will not be known to research staff to ensure blinding.

\section{Standard care}

All participants will receive standard care throughout their time in the study. This may vary with the child's age, diagnosis, functional level and co-morbidities. Our 
previous work shows that advice related to physical activity/diet is rarely part of standard care. ${ }^{37}$ However, any time participants meet with service providers outside of the study context during the course of the study (eg, regular outpatient appointments with medical team, visits to the family doctor), they will request that the service provider competes a brief form that records whether they discussed diet or physical activity and the extent to which solution-focused communication was used. Service providers will also identify if they have any SFC-peds training. Coaches will not be part of the participants' team providing standard care.

\section{Control information}

After randomisation, all participants will be given printed information relating to physical activity and healthy diets based on Health Canada's Eat Well and Be Active Toolkit ( www.health.gc.ca/eatwell-beactive).

\section{Intervention: SFC-peds}

Coaches delivering the intervention will have physiotherapy, therapeutic recreation, health promotion or similar training who have already been trained in SFC-peds. They will undertake an additional half day of training from expert team members on Canadian physical activity and dietary guidelines ${ }^{38}{ }^{39}$ and their application to children with SB and CP. Coaches will then practice goal-setting and coaching with the Coaching expert on the team (SK).

Children randomised into the SFC-peds group $(n=15)$ will be allocated the same coach for up to eight $60 \mathrm{~min}$ SFC-peds sessions over 6 months. The flexibility of SFC-peds means that there is not a strict schedule of coaching sessions. Time is allowed between sessions for children to work on their goals. ${ }^{16}$ Over the 6-month period, sessions will taper off to allow the child practice at sustaining the behaviour change.

The first coaching session will take place in the family's home to establish rapport. First, the coach will support children to identify his/her 'preferred future', that is, the 'big picture' the participant wants to work towards in the context of healthy diet/physical activity and co-create goals that are personally meaningful for the child. Using established SFC techniques ${ }^{40}$ the coach, along with the parents (if appropriate), will then support the child to identify realistic goal attainment strategies based on their own strengths and resources. Parental involvement in the goal-setting will depend on the child's age and abilities and will ensure that goals and goal-attainment strategies are realistic for the child, his/her environmental settings and the family context. Their exact involvement will be documented. In previous research, children with disabilities reached a participation-oriented goal within 3-5 sessions. ${ }^{41}$ In our study, children will each set at least one physical activity or one dietary goal. The number of coaching sessions taken to achieve the child's goals will be examined as part of the feasibility testing, both quantitatively and qualitatively,and will inform future coaching protocols.

To reduce family burden and enhance adherence, all coaching sessions after the initial session will be held remotely using secure online meeting software requiring families only to have internet access. Ninety per cent of Canadians have internet access, ${ }^{42}$ but any instances of internet access being a barrier to study participation will be noted and inform our assessment of study feasibility.

Coaching sessions will always be directed to the child primarily, although parents may provide input if they are needed as a resource to enable the child attain their goal. At every coaching session, coaches will employ SFC-peds best practices by asking key questions that: Elicit any changes since previous sessions (eg, What's better? What worked?); amplify successes (eg, How did you figure that out?); reinforce key learnings (eg, What have you learnt as a result of that success?); and then revisit the child's action plan for appropriate next steps (eg, With your new skills, what's next?). ${ }^{40}$

\section{Patient and public involvement}

All aspects of the protocol described here were reviewed by members of the Holland Bloorview Research Family Engagement Committee (RFEC). Members of the RFEC all have experience of living with a child with a disability and bring this lived experience perspective when providing recommendations to researchers. In addition, the research team includes two parents-one of a child with SB and one of a young person with CP. They provided critical input when designing both the intervention implementation protocol and assessment schedule. They will participate in regular team meetings while the study is being conducted to provide advice as appropriate. The family team members as well as members of the RFEC will assist with knowledge translation (KT) at the end of the study. Study participants will receive an infographic summarising the main findings of the study once complete.

\section{STUDY OUTCOMES AND PROCEDURES \\ Assessment timings}

To assess participant retention, we will use four assessment points over 12 months: time 1 (immediately preceding randomisation); time 2 (immediately postintervention/6 months postrandomisation); time 3 (3months postintervention or 9 months postrandomisation); time 4 (6 months postintervention or 12 months postrandomisation). See table 2 for the time schedule of enrolment, intervention, assessments and follow-up. Assessors will be blinded to the child's group allocation.

\section{Study assessments}

\section{Primary objective}

To evaluate the feasibility of conducting an efficacy trial of a novel, brief, coaching intervention (SFC-peds) for improving and sustaining physical activity and dietary habits in CWPD. 
Table 2 Schedule for enrolment, intervention, assessments and follow-up

\begin{tabular}{|c|c|c|c|c|c|c|c|}
\hline $\begin{array}{l}\text { Baseline } \\
\text { Time } 1\end{array}$ & Randomisation & $\begin{array}{l}\text { Months } 1-5 \\
\text { Coaching begins } \\
\text { within } 2 \text { weeks of } \\
\text { randomisation }\end{array}$ & $\begin{array}{l}\text { Month } 6 \\
\text { Time } 2 \\
\text { postrandomisation† }\end{array}$ & $\begin{array}{l}\text { Month } \\
7-8\end{array}$ & $\begin{array}{l}\text { Month } 9 \\
\text { Time } 3 \\
3 \text { months } \pm 2 \text { weeks } \\
\text { of last coaching } \\
\text { session } ¥\end{array}$ & $\begin{array}{l}\text { Months } \\
10-11\end{array}$ & $\begin{array}{l}\text { Month } 12 \\
\text { Time } 4 \\
6 \text { months } \pm 4 \text { weeks } \\
\text { of last coaching } \\
\text { session§ }\end{array}$ \\
\hline Demographics & & & $\begin{array}{l}\text { Demographics (meds and } \\
\text { sports involvement only) }\end{array}$ & & $\begin{array}{l}\text { Demographics } \\
\text { (meds and sports } \\
\text { involvement only) }\end{array}$ & & $\begin{array}{l}\text { Demographics (meds } \\
\text { and sports involvement } \\
\text { only) }\end{array}$ \\
\hline 6MWT/6MPT & & & 6MWT/6MPT & & 6MWT/6MPT & & 6MWT/6MPT \\
\hline HAES & & & HAES & & HAES & & HAES \\
\hline DSQ & & & DSQ & & DSQ & & DSQ \\
\hline ASDS & & & ASDS & & ASDS & & ASDS \\
\hline PHASES & & & PHASES & & PHASES & & PHASES \\
\hline \multirow[t]{2}{*}{ FEAHQ-R } & & & FEAHQ-R & & FEAHQ-R & & FEAHQ-R \\
\hline & & & $\begin{array}{l}\text { COPM/GAS } \\
\text { (intervention only) }\end{array}$ & & & & \\
\hline \multirow[t]{2}{*}{$\begin{array}{l}\text { Semistructured } \\
\text { survey (all) }\end{array}$} & & $\begin{array}{l}\text { COPM/GAS } \\
\text { (intervention only) }\end{array}$ & $\begin{array}{l}\text { In-depth interview } \\
\text { (intervention } \\
\text { participants+their parents } \\
\text { only) }\end{array}$ & & & & $\begin{array}{l}\text { Follow-up survey } \\
\text { (controls only) }\end{array}$ \\
\hline & & $\begin{array}{l}\text { PRIME-SP } \\
\text { SFFI } \\
\text { (intervention only- } \\
\text { after each coaching } \\
\text { session) }\end{array}$ & & \multicolumn{2}{|c|}{$\begin{array}{l}\text { Photovoice (intervention only) } \\
1-2 \text { photos/month (months } 7-12 \text { ) }\end{array}$} & & $\begin{array}{l}\text { In-depth interview } \\
\text { (intervention + parents } \\
\text { only) }\end{array}$ \\
\hline
\end{tabular}

*Body composition: weight, height/length, waist circumference and skinfold thickness.

$\dagger$ Time 2: 6 months \pm 2 weeks from randomisation for Controls.

$\ddagger$ Time 3: 9 months \pm 2 weeks from randomisation. for Controls

$\S$ Time 4: 12 months \pm 4 weeks from randomisation for Controls.

6MWT/6MPT, 6 min walk test/6 min push test; ASDS, Arc's Self-Determination Scale; COPM, Canadian Occupational Performance Measure;

DSQ, Dietary Screener Questionnaire; FEAHQ-R, Family Eating and Activity Habits Questionnaire-Revised; GAS, Goal Attainment Scaling; HAES, Habitual Activity Estimation Scale; ISCOLE, International Study of Childhood Obesity, Lifestyle and the Environment Questionnaire; PHASES,

Physical activity self-efficacy scale; PRIME-SP, Pediatric Rehabilitation Intervention Measure of Engagement-Service Provider; SEHE, Self-Efficacy for Healthy Eating Scale; SFFI, Solution Focused Coaching Fidelity Instrument.

Trial feasibility will be assessed using preidentified criteria addressing recruitment, attrition, adherence, stratification and fidelity (see table 3). Trial acceptability will be explored using surveys and qualitative interviews at different time points across both the intervention and control groups.

\section{Semistructured survey I}

At time 1, all participants $(n=30)$ and their parents $(n=30)$ will complete a semistructured survey exploring their expectations of, and motivations for, joining the study, as well as their views on healthy lifestyles.

\section{Qualitative interview I}

At time 2 (6months postrandomisation), SFC-peds participants $(n=15)$ and their parents $(n=15)$ will participate in a semistructured qualitative interview to explore: (1) satisfaction with coaching sessions (eg, relationship with coach, experiences of virtual coaching; whether they would recommend it to others); (2) coaching experiences (eg, new opportunities, challenges experienced); (3) perceived optimal coaching dose; (4) perceived impact of SFC-peds on children's (and family's) healthy behaviours (physical activity and diet); and (5) role/experiences of parent involvement in supporting coaching goals and subsequent activities. SFC-peds participants will then be asked to start taking one to two naturalistic photos per month (using either a camera provided or their cellphone) between time 2 and time 4, to provide insights into their lifestyles postcoaching (termed 'Photovoice'). Photovoice uses photographic images taken by participants to help researchers understand what is meaningful for them while also acting as a prompt for rich dialogue and discussion. ${ }^{43}$

\section{Qualitative interview II}

At time 4 (12 months postrandomisation), children and their parents in the SFC-peds group will undertake individual in-depth qualitative interviews to explore their experiences of health and wellness in the 6 months since coaching ended. Prompts may include the perceived impact of coaching, barriers/facilitators to maintaining 


\begin{tabular}{|c|c|c|}
\hline & Success criteria I & Success criteria II \\
\hline Recruitment & $\begin{array}{l}\text { 2-3 participants/ } \\
\text { month recruited over } \\
12 \text { months (for target } \\
\text { sample size } n=30 \text { ). }\end{array}$ & $\begin{array}{l}\geq 10 \% \text { recruitment } \\
\text { response rate achieved } \\
\text { (min. feasible } \mathrm{RCT} \\
\text { response rate). }\end{array}$ \\
\hline Attrition & $\begin{array}{l}85 \% \text { participants } \\
\text { successfully } \\
\text { complete study (ie, } \\
\text { complete T1 and T4 } \\
\text { evaluations). }\end{array}$ & $\begin{array}{l}75 \% \text { participants } \\
\text { complete all } \\
\text { assessments (ie, } \\
\text { protocol adherence). }\end{array}$ \\
\hline Adherence & $\begin{array}{l}\text { Successful } \\
\text { completers } \\
\text { participate } \\
\text { in } \geq 75 \% \text { meetings } \\
\text { with coach. }\end{array}$ & $\begin{array}{l}75 \% \text { of the participants } \\
\text { complete evaluations } \\
\text { in } \leq 2 \text { hours (to assess } \\
\text { burden). }\end{array}$ \\
\hline Stratification & $\begin{array}{l}\text { Intervention/control } \\
\text { groups similar for } \\
\text { age and gender. }\end{array}$ & $\begin{array}{l}\text { Intervention/control } \\
\text { groups comparable } \\
\text { on diagnosis and } \\
\text { functional mobility. }\end{array}$ \\
\hline Fidelity & $\begin{array}{l}\text { High intervention } \\
\text { fidelity (>8/10 on the } \\
\text { Solution-Focused } \\
\text { Fidelity Instrument). }\end{array}$ & $\begin{array}{l}\text { Challenges/ease of } \\
\text { remote coaching } \\
\text { (coach, child, family } \\
\text { report). }\end{array}$ \\
\hline
\end{tabular}

$\mathrm{RCT}$, randomised controlled trial.

physical activity and dietary habits, and any unmet needs. However, the interviews will be guided largely by the participants recounting their experiences. Children's interviews will be guided by their selection of $6-8$ of their photographs taken since time 2 to share with the interviewer and speak in more depth about their feelings and experiences of health and wellness since the coaching sessions. ${ }^{44}$

\section{Survey II}

At time 4 (12 months postrandomisation), children in the control group $(n=15)$ and their parents $(n=15)$ will complete a brief survey regarding what they liked most/ least about the study, any changes in healthy behaviours (physical activity and diet) in the previous 12 months, acceptability of group allocation and acceptability of outcome measure completion (eg, frequency, ability to complete multiple measures at one time, etc).

\section{Qualitative interview-coaches}

At the end of the study, the coaches will be interviewed to explore their experiences of delivering the intervention, for example, challenges/facilitators, optimal coaching doses, use of technology.

\section{Secondary objective}

To determine the responsiveness of outcome measures to SFC-peds coaching over 12 months. (table 4 provides an overview of all outcome measures).

\section{Measurement of participant characteristics}

Demographic information will be gathered at time 1, including sex assigned at birth and gender (if different), age and ethnicity. Diagnoses, medications and sports involvement will be assessed at all four timepoints. Functional mobility will also be assessed at every time point using the 6 minute walk test for ambulatory children ${ }^{45}$ and the 6 minute push test for those using a manual wheelchair. ${ }^{46}$ If a child meeting the inclusion criteria uses an electric wheelchair, functional mobility will not be assessed.

\section{Issue identification and goal attainment (primary outcome measure)}

The validated Canadian Occupational Performance Measure (COPM) identifies the person-centred goal performance issues individuals wish to improve and assesses changes in performance and satisfaction over time. ${ }^{47}$ The identified goal issue will then be operationalised using Goal Attainment Scaling (GAS), through the use of rigorous procedures to ensure that all five attainment levels are mutually exclusive and measurable (see table 5 , for an example of COPM and GAS goals). To minimise bias, GAS and COPM reassessment will be conducted by a coach who has not worked with the child.

\section{Behavioural outcomes}

To assess physical activity, we will use the Habitual Activity Estimation Scale ${ }^{48}$ which is a child self-report measure of the time spent inactive, somewhat inactive, somewhat active and very active. The scale shows good correlation with moderate to vigorous physical activity measured by accelerometry in our population. ${ }^{49}$ The child self-report Dietary Screener Questionnaire will be used to assess dietary intake over the past 30 days which has been validated against 24 hours recall. ${ }^{50}$

\section{Psychosocial outcomes}

The child-reported Arc's Self-Determination Scale has excellent reliability/validity with children with disabilities $^{18}$ and will provide insight into potential mechanisms of behaviour change. The Physical Activity Self-Efficacy Scale assesses confidence in the ability to be physically active when faced with challenges and has good internal consistency $(\alpha=0.54-0.71)$ and test-retest reliability (Intraclass Correlation Coefficient $($ ICC $)=0.61-0.82){ }^{51}$ High self-efficacy scores are associated with greater moderate-vigorous physical activity. ${ }^{52}$ The Self-Efficacy for Healthy Eating scale assesses participants' self-reported feelings of competence for making healthy food choices in social, emotional and typical situations. Higher scores are associated with healthy food intake $(\beta=0.33, \mathrm{p}<0.01)$. Test-retest reliability is high $(\mathrm{ICC}=0.80) .^{53}$

\section{Body composition}

Anthropometric assessments will be conducted according to established protocols. ${ }^{54}$ Rigorous training will be provided to assessors and strong inter-rater and intrarater reliability established prior to data collection 
Table 4 Outcome measures used in study

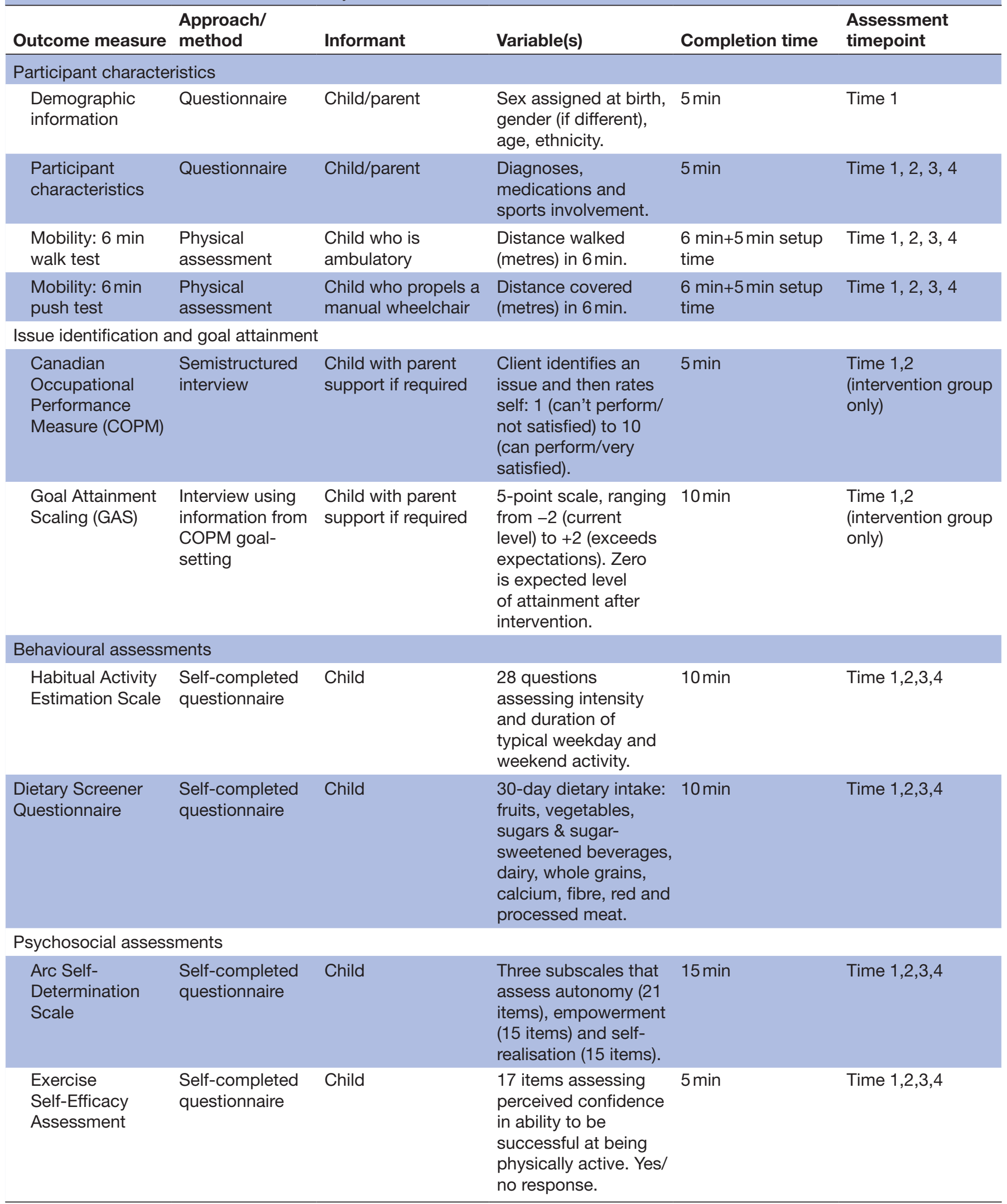

Continued 
Table 4 Continued

\begin{tabular}{|c|c|c|c|c|c|}
\hline Outcome measure & $\begin{array}{l}\text { Approach/ } \\
\text { method }\end{array}$ & Informant & Variable(s) & Completion time & $\begin{array}{l}\text { Assessment } \\
\text { timepoint }\end{array}$ \\
\hline $\begin{array}{l}\text { Self-Efficacy for } \\
\text { Healthy Eating }\end{array}$ & $\begin{array}{l}\text { Self-completed } \\
\text { questionnaire }\end{array}$ & Child & $\begin{array}{l}\text { Nine items assessing } \\
\text { confidence eating } \\
\text { 'healthy foods' across } \\
\text { three domains: Social, } \\
\text { emotional and normal } \\
\text { situations. Response } \\
\text { on 5-point Likert } \\
\text { scale. }\end{array}$ & $5 \mathrm{~min}$ & Time 1,2,3,4 \\
\hline
\end{tabular}

Body composition

\begin{tabular}{|c|c|c|c|c|c|}
\hline Weight & $\begin{array}{l}\text { Physical } \\
\text { assessment }\end{array}$ & Assessor & $\begin{array}{l}\text { Chair scale, to nearest } \\
100 \mathrm{~g} .\end{array}$ & $5 \min$ & Time 1,2,3,4 \\
\hline Height/length & $\begin{array}{l}\text { Physical } \\
\text { assessment }\end{array}$ & Assessor & $\begin{array}{l}\text { Standing height } \\
\text { or supine length } \\
\text { (segmental if } \\
\text { contractures); ulna } \\
\text { and arm length as } \\
\text { proxies if height/ } \\
\text { length not possible. }\end{array}$ & $5 \min$ & Time 1,2,3,4 \\
\hline $\begin{array}{l}\text { Waist } \\
\text { circumference }\end{array}$ & $\begin{array}{l}\text { Physical } \\
\text { assessment }\end{array}$ & Assessor & $\begin{array}{l}\text { Flexible tape measure } \\
\text { at the narrowest level } \\
\text { between the lower } \\
\text { costal border and the } \\
\text { iliac crest, over light } \\
\text { clothing. }\end{array}$ & $5 \mathrm{~min}$ & Time $1,2,3,4$ \\
\hline
\end{tabular}

\begin{tabular}{|c|c|c|c|c|c|}
\hline \multicolumn{6}{|c|}{ Home and environment assessment } \\
\hline $\begin{array}{l}\text { Revised Family } \\
\text { Eating and } \\
\text { Activity Habits } \\
\text { Questionnaire }\end{array}$ & $\begin{array}{l}\text { Parent- } \\
\text { completed } \\
\text { questionnaire }\end{array}$ & Parent & $\begin{array}{l}32 \text { items about the } \\
\text { health behaviours } \\
\text { of family members } \\
\text { as well as the } \\
\text { nature of the home } \\
\text { environment. }\end{array}$ & $10 \mathrm{~min}$ & Time 1,2,3,4 \\
\hline $\begin{array}{l}\text { International } \\
\text { Study of } \\
\text { Childhood } \\
\text { Obesity, } \\
\text { Lifestyle and } \\
\text { the Environment } \\
\text { Questionnaire }\end{array}$ & $\begin{array}{l}\text { Parent- } \\
\text { completed } \\
\text { questionnaire }\end{array}$ & Parent & $\begin{array}{l}\text { Full scale is 103- } \\
\text { items assessing } \\
\text { the child's } \\
\text { neighbourhood and } \\
\text { home environments. } \\
\text { Responses vary from } \\
4 \text { to 5-point Likert } \\
\text { scale, yes/no and } \\
\text { frequency. }\end{array}$ & $10 \mathrm{~min}$ & $\begin{array}{l}\text { Full scale: time } 1,4 \\
\text { Sub-scales } \\
\text { D,E,G,H: time } 2,3 \\
\text { only }\end{array}$ \\
\hline \multicolumn{6}{|l|}{ Coach measures } \\
\hline $\begin{array}{l}\text { Solution } \\
\text { Focused Fidelity } \\
\text { instrument }\end{array}$ & $\begin{array}{l}\text { Self-complete } \\
\text { questionnaire }\end{array}$ & Coach & $\begin{array}{l}13 \text { items rating key } \\
\text { aspects of Solution } \\
\text { Focused Coaching } \\
\text { best practices on a } \\
10 \text {-point Likert scale. }\end{array}$ & $5 \mathrm{~min}$ & $\begin{array}{l}\text { After every } \\
\text { coaching session }\end{array}$ \\
\hline
\end{tabular}

Continued 
Table 4 Continued

\begin{tabular}{|c|c|c|c|c|c|}
\hline Outcome measure & $\begin{array}{l}\text { Approach/ } \\
\text { method }\end{array}$ & Informant & Variable(s) & Completion time & $\begin{array}{l}\text { Assessment } \\
\text { timepoint }\end{array}$ \\
\hline $\begin{array}{l}\text { Pediatric } \\
\text { Rehabilitation } \\
\text { Intervention } \\
\text { Measure of } \\
\text { Engagement- } \\
\text { Service Provider }\end{array}$ & $\begin{array}{l}\text { Self-complete } \\
\text { questionnaire }\end{array}$ & Coach & $\begin{array}{l}\text { Three-part } \\
\text { questionnaire: (1) } \\
\text { One overall rating of } \\
\text { child's engagement } \\
\text { during the coaching } \\
\text { session; (2) Likert } \\
\text { scale rating on three } \\
\text { different aspects } \\
\text { of engagement; (3) } \\
\text { Any comments on } \\
\text { factors that may have } \\
\text { influenced the child's } \\
\text { engagement during } \\
\text { the session. }\end{array}$ & $5 \mathrm{~min}$ & $\begin{array}{l}\text { After every } \\
\text { coaching session }\end{array}$ \\
\hline
\end{tabular}

Table 5 Example of 'preferred future', goals and attainment strategies (10-year-old child)

\section{Preferred future}

I feel fit and can keep up with my friends on the playground

\section{COPM goal}

I want to be more physically

active

\section{GAS goals}

Present level or much less than expected

$(-2)$

Somewhat less than expected $(-1)$

Expected level or programme I have tried a new sport or goal (0)

Somewhat better than expected

$(+1)$

Much better than expected I attend two sports groups $(+2)$ regularly

Goal attainment strategies

Ask my friends what sports they play

Check out my local parks and recreation website

Ask my mother to take me to visit an activity I am interested in

Try wheelchair basketball with my cousin

COPM, Canadian Occupational Performance Measure; GAS, Goal Attainment Scaling. commencing. Weight will be assessed using a chair scale. Standing height or supine length will be measured. For those with severe contractures, supine length will be based on segmental measurement. Where this is not possible, arm span and ulna length will be measured as a proxy for height. ${ }^{55}$ Body mass index will be calculated from weight and height or length as $\mathrm{kg} / \mathrm{m}^{2}$ and classified using Centers for Disease Control and Prevention cut-offs (85th-95th percentile=overweight, above 95th percentile $=$ obese). Waist circumference will also be measured as it has been shown to correlate well with fat mass as measured by dual-energy X-ray absorptiometry. ${ }^{56}$ Tricep and subscapular skinfold thickness will be assessed and the Slaughter equation used to assess body fat. ${ }^{57}$

\section{Home and environment information and outcomes}

The parent-reported Revised Family Eating and Activity Habits Questionnaire assesses the health behaviours of family members as well as the nature of the home environment, and has strong test-retest reliability $(0.76-0.89) .^{58}$ These data will allow us to examine the impact of the coaching on the family over time, which will be further examined in qualitative interviews. Questions from the International Study of Childhood Obesity, Lifestyle and the Environment survey about the child's environment (eg, accessibility of play areas) will also be asked. ${ }^{59}$

\section{Intervention fidelity and child engagement}

After each coaching session, coaches will complete a standardised fidelity measure to ensure intervention consistency. ${ }^{60}$ Participant engagement in each session will be rated by the coaches using the Pediatric Rehabilitation Intervention Measure of Engagement-Service Provider. ${ }^{41}$

\section{DATA ANALYSES}

The data will be entered in an Access Database that will provide drop-down menus and will restrict values within the range allowed for each variable. All statistical analyses will use SAS/STAT software. ${ }^{61}$ Although inferential 
statistics are not required in feasibility studies, ${ }^{29}$ we will explore preliminary effects of the SFC-peds intervention on the main outcomes through two-way repeated measures Analysis of Variance(ANOVA) to see changes on variables over time and between groups, followed by an Analysis of Covariance (ANCOVA) using T1 as a covariate to control basal variability. The GLIMMIX procedure of SAS will be used for that purpose. Estimates of effect sizes with $95 \%$ CIs will be calculated. These will provide important information for sample size calculation in future efficacy trials.

Feasibility will also be assessed with descriptive statistics compared against our a priori success criteria. We will explore any sample/group differences between completers (ie, those who complete time 1 and time 4 measures) and non-completers. We will also determine if there are sample and outcome variable differences (means) between sites, diagnoses and functional mobility.

The software NVIVO V.10 $10^{62}$ will be used to manage the qualitative data. Transcripts from interview I (SFC-peds group at time 2) will undergo conventional content analysis $^{63}$ to explore the immediate perceived impact of the coaching sessions. Data will be coded guided by the data and then sorted into categories. ${ }^{64}$ Transcripts from the coach interviews will be analysed in a similar manner. We will use inductive thematic analysis from a relativist ontological position to analyse the time 4 interviews (interview II), drawing on the phenomenological tradition. ${ }^{65}$ This analytic approach is consistent with our intent to explore the child and family's experiences of health and wellness following the coaching and any changes in how they make sense of their social and personal world. ${ }^{66} 67$ Once transcribed, the research team will read the transcripts and develop codes by noting words, phrases or data segments that occur commonly in participants' narratives. Similar codes will then be grouped, from which a consolidated list of master themes will be created that show patterns in participant experiences. Characteristics (eg, child age, gender, diagnosis and mobility) will be considered to understand the context of the participants' experiences. Code-recode, peer examination and team discussions will help establish trustworthiness. ${ }^{68}$

Measure responsiveness will be established by prepost intervention differences using effect sizes (Cohen's d) and CIs both within and between groups. It is well accepted to examine mean score changes for clinically significant differences pre and post intervention without calculating statistical significance (eg, a score change of at least two points on the COPM is considered clinically significant) ${ }^{47}$ We will therefore assess the potential value of SFC-peds over only receiving printed materials by examining goal scores over time. Our secondary outcomes will be compared with behaviour change (goal attainment) for concordance (eg, whether successful goal attainment corresponds with increased self-determination). We will examine differences in outcome measures by disability, mobility, gender and age.

\section{ETHICS AND DISSEMINATION}

All participants will provide written informed consent to the trained research coordinator prior to any study activities. Identifying information for potential participants will be stored on an encrypted server, in a password protected folder. If a participant chooses not to participate in the study, his/her identifying information will be deleted immediately. Identifying information for those who agree to participate in the study will be stored on the same encrypted server, in a password-protected folder that requires authorisation from a member of the research team. This information will be retained for the life of the study. The principal investigator will be the guardian of the dataset and only allow authorised individuals access.

Given that we are providing printed information on healthy lifestyles to all study participants, every child will have exposure to information on healthy habits, not just those in the intervention group. In order to reduce burden on families, our intervention (SFC-peds) is largely virtual.

Using a KT planning template, ${ }^{69}$ we will ensure our findings have maximum reach yet are appropriate for the nature of feasibility study outcomes. Integrated KT is being promoted by the involvement of clinical, family and knowledge user stakeholders, to ensure that the outputs meet the needs of the end users. ${ }^{70}$ End of grant KT will include dissemination of study findings using traditional knowledge diffusion strategies (eg, conference presentations and publications) and communications to lay forums with summaries, stories and infographics. We will use the Template for the Intervention Description and Replication checklist ${ }^{71}$ when we report the results from the trial, so that we can provide information on context, tailoring, modifications and so on. We will track all KT activities.

\section{DISCUSSION}

This protocol describes a RCT to evaluate the feasibility of delivering a novel, complex intervention to promote healthy lifestyles in children with SB and CP (SFC-peds), including the acceptability of both the intervention and study participation for participants. This is a critical first step given that we currently do not have robust evidence regarding intervention strategies to improve and sustain healthy lifestyles in CWPD. ${ }^{5}$ Any complex intervention requires rigorous evaluation in order to provide evidence-based recommendations to improve short-term and long-term health. This feasibility study will therefore provide critical guidance for any future efficacy trial to ensure that it generates clinically meaningful results. ${ }^{26}$ The strengths of this study include the involvement of two populations with demonstrated high needs regarding healthy lifestyles, as well as the use of rigorous methodology to evaluate a complex intervention. Using two distinct populations will help guide future decisions about whether single or mixed populations should be included in the same trial. Strengths also include the use 
of a standardised yet flexible intervention, with rigorous training and fidelity measures. The use of a priori feasibility success criteria adheres to best practices ${ }^{72}$ and integrating qualitative inquiry lends insight into potential mechanisms of change and barriers to implementation. ${ }^{32}$

Given that feasibility studies are not powered to assess intervention efficacy, the proposed feasibility RCT will not confirm whether SFC-peds should be routinely recommended for CWPD. However, addressing the feasibility (study design, methods, processes) and acceptability (family/child/clinician satisfaction, perceived usefulness) of an intervention before any efficacy trial begins increases the later likelihood of success and confidence in the findings. ${ }^{26}$ This study will recruit from two sites in one area of Canada which may limit the generalisability of the findings. However, both sites serve diverse socio-cultural communities.

\section{Author affiliations}

${ }^{1}$ Bloorview Research Institute, Holland Bloorview Kids Rehabilitation Hospital, Toronto, Ontario, Canada

${ }^{2}$ Dalla Lana School of Public Health, University of Toronto, Toronto, Ontario, Canada ${ }^{3}$ Rehabilitation Sciences Institute, University of Toronto, Toronto, Ontario, Canada ${ }^{4}$ Institute of Biomaterials \& Biomedical Engineering, University of Toronto, Toronto, Canada

${ }^{5}$ Holland Bloorview Kids Rehabilitation Hospital, Toronto, Ontario, Canada

${ }^{6}$ Faculty of Medicine, University of Toronto, Toronto, Ontario, Canada

${ }^{7}$ Child Development and Exercise Center, Wilhelmina's Children Hospital, University Medical Center Utrecht, Utrecht University, Utrecht, Netherlands

${ }^{8}$ Netherlands Institute for Health Services Research (NIVEL), Utrecht, Netherlands ${ }^{9}$ Occupational Science \& Occupational Therapy, University of Toronto, Toronto, Canada

${ }^{10}$ Center for Interdisciplinary Research in Rehabilita, CIUSSS-CN, Quebec City, Quebec, Canada

${ }^{11}$ Department of Rehabilitation, Faculty of Medicine, Université Laval, Quebec City,

Quebec, Canada

${ }^{12}$ Department of Psychiatry and Neuroscience, Laval University, Quebec City, Quebec, Canada

Acknowledgements The authors wish to thank Patricia Baldwin for advice on the SFC-peds intervention. We also thank Jan Magee, Meredith Sandles and members of Holland Bloorview Kids Rehabilitation Hospital Research Family Engagement Committee for reviewing the original protocol.

Contributors ACM conceptualised the project, wrote the protocol and drafted the manuscript. EB reviewed and provided input on study design. LC advised on anthropometric assessment methods and training protocols. PTC provided expertise on medical considerations for children with spina bifida and cerebral palsy and the coach training protocol. JFdeG participated in the early design of the protocol and provided expertise on physical activity assessment. SK contributed training in SFC-peds and implementation of goal attainment measures. GK provided input on the conceptual basis and key features of the SFC-peds intervention. TL provided input on the implementation of the protocol and assessment schedule. DM contributed to the conceptualisation and design of the study and writing of the protocol. CM provided expertise on randomisation methods and statistical analysis. HM contributed methodological expertise in the design of the study and the research protocol. FM contributed to writing the qualitative research and photovoice components of the protocol. HS contributed to the early conceptualisation of the protocol and study design. All authors have read and agree with the contents of the final manuscript.

Funding This work is supported by the Canadian Institutes of Health Research (grant \#153189). The sponsor is Holland Bloorview Kids Rehabilitation Hospital. Neither the funders nor sponsor not have any role in the study design; collection, management, analysis, and interpretation of data; writing of the report; or the decision to submit the report for publication.

Competing interests None declared.
Patient consent for publication Not required.

Ethics approval Ethical approval has been obtained for this study from Holland Bloorview Kids Rehabilitation Hospital's Research Ethics Board (Ref \# 17-752).

Provenance and peer review Not commissioned; externally peer reviewed.

Open access This is an open access article distributed in accordance with the Creative Commons Attribution Non Commercial (CC BY-NC 4.0) license, which permits others to distribute, remix, adapt, build upon this work non-commercially, and license their derivative works on different terms, provided the original work is properly cited, appropriate credit is given, any changes made indicated, and the use is non-commercial. See: http://creativecommons.org/licenses/by-nc/4.0/

\section{REFERENCES}

1. Bauman A, Craig CL. The place of physical activity in the WHO Global Strategy on Diet and Physical Activity. Int J Behav Nutr Phys Act 2005;2:10

2. Colley R, Garriguet I, Craig C, et al. Physical activity of canadian children and youth: Accelerometer results from 2007-2009. canadian health measures survey 2011:1-9.

3. Statistics Canada. Participation and activity limitation survey 2006: Families of children with disabilities in canada. Ottawa, 2008.

4. Hogan A, McLellan L, Bauman A. Health promotion needs of young people with disabilities-a population study. Disabil Rehabil 2000;22:352-7.

5. Rimmer JH, Rowland JL, Yamaki K. Obesity and secondary conditions in adolescents with disabilities: addressing the needs of an underserved population. J Adolesc Health 2007;41:224-9.

6. Centres for Disease and Control and Prevention. National center on birth defects and developmental disabilities (ncbddd). 2016;6 http:// www.cdc.gov/ncbddd/index.html.

7. Grammatikopoulou MG, Daskalou E, Tsigga M. Diet, feeding practices, and anthropometry of children and adolescents with cerebral palsy and their siblings. Nutrition 2009;25:620-6.

8. Buffart LM, Westendorp T, van den Berg-Emons RJ, et al. Perceived barriers to and facilitators of physical activity in young adults with childhood-onset physical disabilities. J Rehabil Med 2009;41:881-5.

9. McPherson AC, Keith R, Swift JA. Obesity prevention for children with physical disabilities: a scoping review of physical activity and nutrition interventions. Disabil Rehabil 2014;36:1573-87.

10. McPherson A, Ball G, Maltais D, et al. A call to action: Setting the research agenda for addressing obesity and weight-related topics in children with physical disabilities. Childhood Obesity 2016;12:1-11.

11. de Groot JF, Takken T, van Brussel M, et al. Randomized controlled study of home-based treadmill training for ambulatory children with spina bifida. Neurorehabil Neural Repair 2011;25:597-606.

12. McPherson AC, Lindsay S. How do children with disabilities view 'healthy living'? A descriptive pilot study. Disabil Health J 2012;5:201-9.

13. Olsen JM, Nesbitt BJ. Health coaching to improve healthy lifestyle behaviors: an integrative review. Am J Health Promot 2010;25:e1-e12.

14. Findholt NE, Michael YL, Davis MM, et al. Environmental influences on children's physical activity and diets in rural oregon: Results of a youth photovoice project. Online J Rural Nurs Health Care 2010;10:11-20.

15. Graham F, Rodger S, Ziviani J. Effectiveness of occupational performance coaching in improving children's and mothers' performance and mothers' self-competence. Am J Occup Ther 2013;67:10-18

16. Baldwin P, King G, Evans J, et al. Solution-focused coaching in pediatric rehabilitation: an integrated model for practice. Phys Occup Ther Pediatr 2013;33:467-83.

17. Grant AM. Making positive change: A randomized study comparing solution-focused vs. Problem-focused coaching questions. Journal of Systemic Therapies 2012;31:21-35.

18. Wehmeyer M. A functional model of self-determination: Describing development and implementing instruction. Focus on Autism and Other Developmental Disabilities 1999;14:53-62.

19. Abraham C, Kelly MP, West R, et al. The UK national institute for health and clinical excellence public health guidance on behaviour change: a brief introduction. Psychol Health Med 2009;14:1-8.

20. Grant AM. Autonomy support, relationship satisfaction and goal focus in the coach-coachee relationship: which best predicts coaching success? Coaching: An International Journal of Theory, Research and Practice 2014;7:18-38.

21. Bandura A. Self-efficacy: In. Ramachaudran V, ed. Encyclopedia of human behavior. New York: Academic Press, 1994:71-81. 
22. Ryan RM, Deci EL. Self-determination theory and the facilitation of intrinsic motivation, social development, and well-being. Am Psychol 2000;55:68-78.

23. Visser C. Self-determination theory meets solution-focused change: Autonomy, competence and relatedness support in action. InterAction- The Journal of Solution Focus in Organisations 2010;2:7-26.

24. Spence G, Oades L. Coaching with self-determination in mind: Using theory to advance evidence- based coaching practice. International Journal of Evidence Based Coaching and Mentoring 2011;9:37-55.

25. Passarelli A. The heart of helping: Psychological and physiological effects of contrasting coaching interventions. Ohio: Sase Western Reserve University, Weatherhead School of Management, 2014. D. dissertation, Editor.

26. Craig P, Dieppe P, Macintyre S, et al. Developing and evaluating complex interventions: New guidance, 2010:1-39.

27. Thabane L, Ma J, Chu R, et al. A tutorial on pilot studies: the what, why and how. BMC Medical Research Methodology 2010;10:10-11.

28. Clark P, Macarthur J. Children with physical disability: gaps in service provision, problems joining in. J Paediatr Child Health 2008;44:455-8.

29. Shanyinde M, Pickering RM, Weatherall M. Questions asked and answered in pilot and feasibility randomized controlled trials. BMC Med Res Methodol 2011;11:117.

30. Kamath CC, Vickers KS, Ehrlich A, et al. Clinical review: behavioral interventions to prevent childhood obesity: a systematic review and metaanalyses of randomized trials. J Clin Endocrinol Metab 2008;93:4606-15.

31. Fjeldsoe B, Neuhaus M, Winkler E, et al. Systematic review of maintenance of behavior change following physical activity and dietary interventions. Health Psychol 2011;30:99-109.

32. Campbell M, Fitzpatrick R, Haines A, et al. Framework for design and evaluation of complex interventions to improve health. BMJ 2000;321:694.

33. Buffart $L$, van den Berg-Emons $H$, van Wijien-Hempel $M$, et al. Health-related physical fitness of adolescents and young adults with myelomeningocele. Eur J Appl Physiol 2008;108:181-8.

34. Maltais DB, Wiart L, Fowler E, et al. Health-related physical fitness for children with cerebral palsy. J Child Neurol 2014;29.

35. Arain M, Campbell MJ, Cooper CL, et al. What is a pilot or feasibility study? A review of current practice and editorial policy. BMC Med Res Methodol 2010;10:67.

36. Draper A, Swift JA. Qualitative research in nutrition and dietetics: data collection issues. J Hum Nutr Diet 2011;24:3-12.

37. McPherson A, Swift J, Yung E, et al. A retrospective medical record review of overweight and obesity in children with spina bifida. Disability and Rehabilitation 2013;35:2123-31.

38. Health Canada. Canada's food guide: Health Canada, 2009. http:// www.hc-sc.gc.ca/fn-an/food-guide-aliment/index-eng.php.

39. Canadian Society for Exercise Physiology. Canadian physical activity guidelines. 2012 http://files.participaction.com/physicalactivityguid elines/csepguidelinesqa e.pdf.

40. Berg, I. and Szabo, P., Brief coaching for lasting solutions. New York: WW Norton and Company, Inc, 2005.

41. King G, Schwellnus H, Keenan S, et al. Youth engagement in pediatric rehabilitation: service providers' perceptions in a real-time study of solution-focused coaching for participation goals. Phys Occup Ther Pediatr 2018 (Early online 05 Jan 2018).

42. Poushter J. Smartphone ownership and internet usage continues to climb in emerging economies, 2016.

43. Croghan R, Griffin C, Hunter J, et al. YOung people's constructions of self: Notes on the use and analysis of the photo-elicitation methods. Int J Soc Res Methodol 2008;11:345-56.

44. Rose G. Visual methodologies: An introduction to the interpretation of visual materials. London: Sage, 2001.

45. Enright PL. The six-minute walk test. Respir Care 2003;48:783-5

46. Verschuren O, Ketelaar M, De Groot J, et al. Reproducibility of two functional field exercise tests for children with cerebral palsy who self-propel a manual wheelchair. Dev Med Child Neurol 2013;55:185-90.
47. Law M, Baptiste S, Carswell A, et al. Canadian occupational performance measure. 4th ed. Ottawa, ON: CAOT Publications ACE, 2005.

48. Hay JA, University B, Cairney J. Development of the habitual activity estimation scale for clinical research: A systematic approach. Pediatric Exercise Science 2006;18:193-202.

49. Dufour S, Lansing N, Bouyer L, et al. The physical activity-related perceptions of youth with cerebral palsy are associated with their physical activity performance and fitness. Developmental Medicine and Child Neurology 2015;57(S5):63-4.

50. National Cancer Institute Dietary screener in the nhanes 2009-10, 2010.

51. Brown $\mathrm{H}$, Hume $\mathrm{C}$, ChinAPaw M. Validity and reliability of instruments to assess potential mediators of children's physical activity: A systematic review. J Sci Med Sport 2009;12:539-48.

52. Saunders RP, Pate RR, Felton G, et al. Development of questionnaires to measure psychosocial influences on children's physical activity. Prev Med 1997;26:241-7.

53. Fitzgerald A, Heary C, Kelly C, et al. Self-efficacy for healthy eating and peer support for unhealthy eating are associated with adolescents' food intake patterns. Appetite 2013:63:48-58.

54. Centers for Disease Control and Prevention. National health and nutrition examination survey (nhanes): Anthropometry procedures manual. Centers for Disease Control and Prevention: Atlanta, 2017.

55. Gauld LM, Kappers J, Carlin JB, et al. Height prediction from ulna length. Dev Med Child Neurol 2004;46:475-80.

56. Liu LF, Roberts R, Moyer-Mileur L, et al. Determination of body composition in children with cerebral palsy: bioelectrical impedance analysis and anthropometry vs dual-energy $x$-ray absorptiometry. $J$ Am Diet Assoc 2005;105:974-797.

57. Slaughter MH, Lohman TG, Boileau RA, et al. Skinfold equations for estimation of body fatness in children and youth. Hum Biol 1988;60:709-23.

58. Golan M. Fifteen years of the Family Eating and Activity Habits Questionnaire (FEAHQ): an update and review. Pediatr Obes 2014;9:92-101.

59. Katzmarzyk PT, Barreira TV, Broyles ST, et al. The International Study of Childhood Obesity, Lifestyle and the Environment (ISCOLE): design and methods. BMC Public Health 2013;13:1-13.

60. Lehmann P, Patton J. The development of a solution-focused fidelity instrument: A pilot study., in Solution-focused brief therapy: A handbook of evidence-based practice. Franklin C, ed. New York: Oxford University Press, Inc, 2012.

61. SAS Institute Inc. Sas system for windows 9.4. Cary, NC, USA, 2015.

62. Nvivo qualitative data analysis software. QSR International Pty Ltd, 2012. V10.

63. Elo $\mathrm{S}, \mathrm{Kyngäs} \mathrm{H}$. The qualitative content analysis process. J Adv Nurs 2008;62:107-15.

64. Hsieh HF, Shannon SE. Three approaches to qualitative content analysis. Qual Health Res 2005;15:1277-88.

65. Fade SA, Swift JA. Qualitative research in nutrition and dietetics: data analysis issues. J Hum Nutr Diet 2011;24:106-14.

66. Smith JA. Evaluating the contribution of interpretative phenomenological analysis. Health Psychology Review 2011;5:9-27.

67. Jachyra P, Anagnostou E, Knibbe TJ, et al. Weighty conversations: Caregivers', children's, and clinicians' perspectives and experiences of discussing weight-related topics in healthcare consultations. Autism Res 2018;11:1500-10.

68. Shenton AK. Strategies for ensuring trustworthiness in qualitative research projects. Education for Information 2004;22:63-75.

69. Barwick M. Knowledge translation planning template- r. 2011. http:// www.melaniebarwick.com/training.php

70. Canadian Institutes of Health Research, Guide to knowledge translation planning at cihr: Integrated and end-of-grant approaches. Ottawa, 2012.

71. Hoffmann TC, Glasziou PP, Boutron I, et al. Better reporting of interventions: template for intervention description and replication (TIDieR) checklist and guide. BMJ 2014;348:g1687.

72. Billingham SA, Whitehead AL, Julious SA. An audit of sample sizes for pilot and feasibility trials being undertaken in the united kingdom registered in the united kingdom clinical research network database. BMC Med Res Methodol 2013;13:104. 